\title{
LUMBO-SACRAL FUSION WITH SPRING FIXATION
}

\author{
C. G. Attenborough, Hastings, and M. T. Reynolds, Warwick, England
}

\begin{abstract}
A method of posterior lumbo-sacral fusion is described in which springs are used to fix the grafts and to maintain immobilisation. Fifty patients with lumbar disc degeneration or spondylolisthesis have been reviewed. The results have been assessed clinically by grading the symptoms before and after operation. Stay in hospital has been short and return to work rapid. There has been a high proportion of good results.
\end{abstract}

This paper describes a new method of lumbo-sacral fusion based on a modification of the Bosworth H-graft described by Chandler (Newman 1951). The technique was developed after a series of posterior lumbo-sacral fusions had been reviewed. All the fusions had been done in one orthopaedic unit but by several surgeons (Attenborough 1955). The Bosworth $\mathrm{H}$-graft had been used in most of the successful operations, but the incidence of sound fusion was highest in a small number of cases in which, according to the Chandler technique, longitudinal grafts had been laid on the rawed laminae on either side of the spinous processes with one or more transverse grafts across them between the spinous processes. The spinous processes of the upper and lower vertebrae to be fused were linked together under pressure with wire which passed across the back of the transversely placed grafts. When the lumbar spine was flexed the wire pressed the grafts anteriorly and kept them in close contact with the laminae. In practice the wire, being inelastic, tended to cut out from its bony attachment or to break. Once loose, it no longer maintained its pressure and the grafts could lose contact with the laminae.

To overcome the problem a special spring was developed that would maintain a continuous pressure on the graft and graft bed in whatever position the spine was held. This spring, of much the same shape and size as those used for hanging net curtains, was made from biologically inert stainless steel.

\section{THE SPRING}

The springs (Fig. 1) are made from hand-drawn 20 S.W.G. stainless steel (E.N. $58 \mathrm{~J}$ ) with a diameter of 0.75 millimetre. The wire is close wound. The outside diameter of the spring, which is 4.3 millimetres, governs the extensibility. After winding, the springs are mechanically and electrolytically polished and cleaned ultrasonically. The spring may be stretched to nearly twice its original length before going into a permanent stretch set (Fig. 2). For spinal fusion a 50 per cent increase in length is used to give a tension of 6 kilograms.

The springs are supplied in 37.5-centimetre lengths and are easily cut to size.
Hooks with threaded shanks, made from the same material, are screwed into the ends of the spring to be used: the hooks are of large or small radius (Fig. 1).

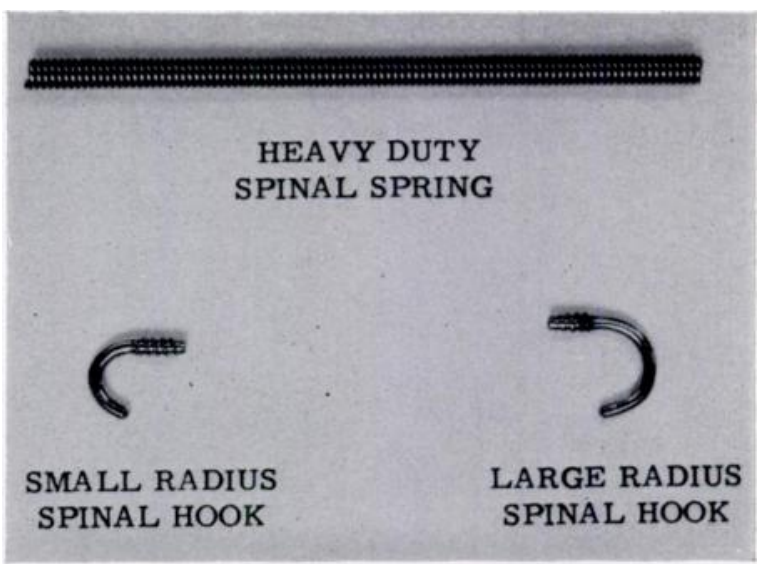

Fig. 1

Spring and hooks.

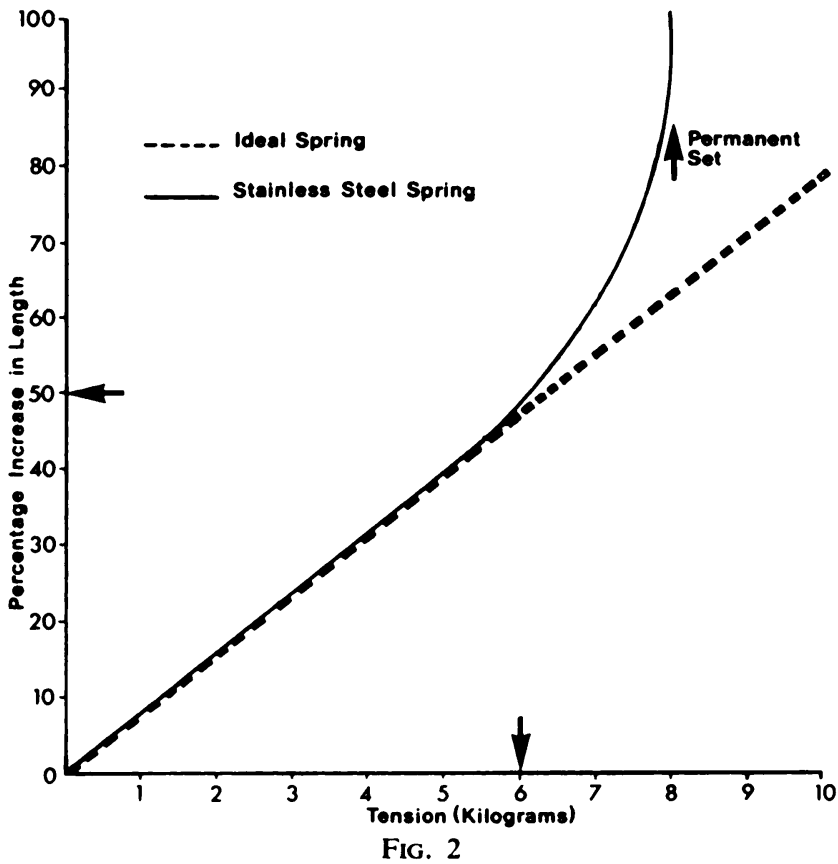

Graph showing the tension produced by stretching the spring.

C. G. Attenborough, M.Chir., F.R.C.S., Consultant Orthopaedic Surgeon, Royal East Sussex Hospital, Hastings, Sussex, England. M. T. Reynolds, F.R.C.S., Orthopaedic Department, Warwick General Hospital, Lakin Road, Warwick, England. 


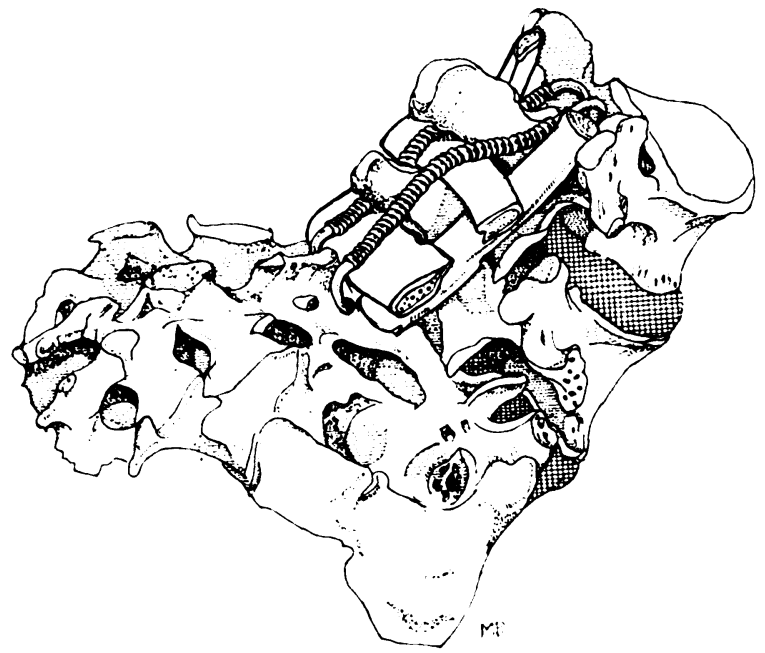

FIG. 3

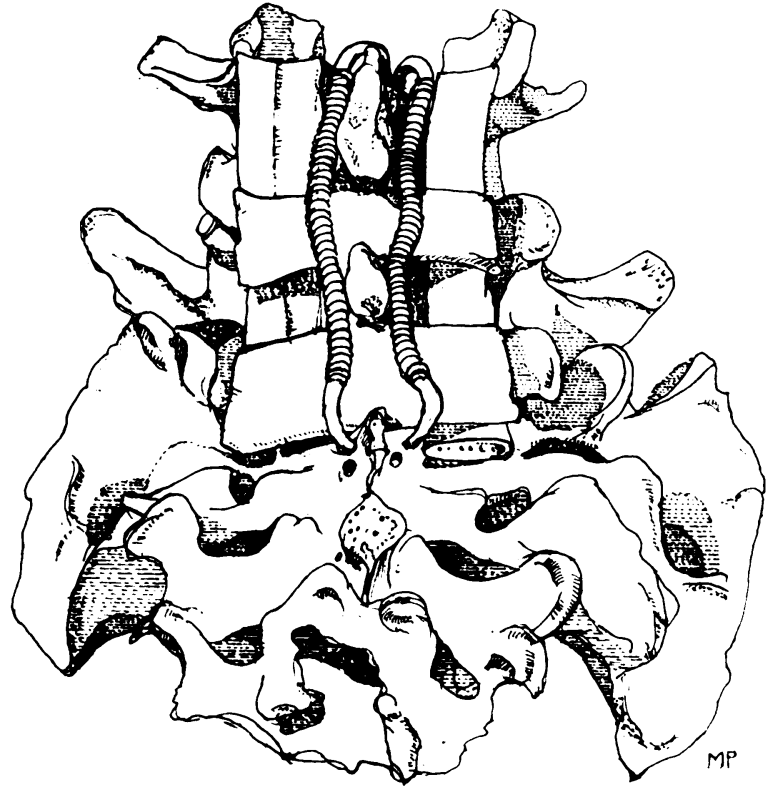

FiG. 4

Line drawings showing springs and grafts in position from the fourth lumbar vertebra to the sacrum.

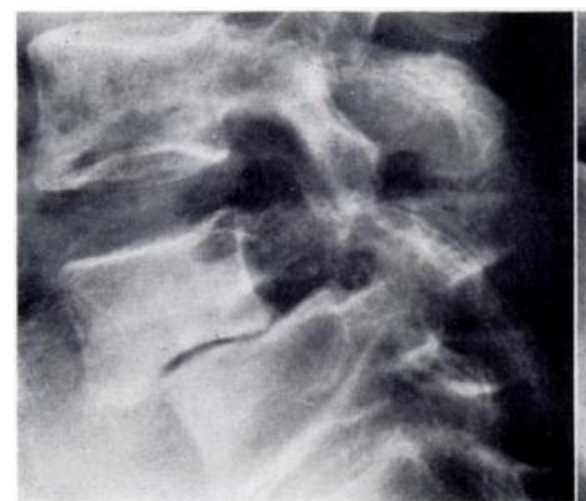

Fig. 5

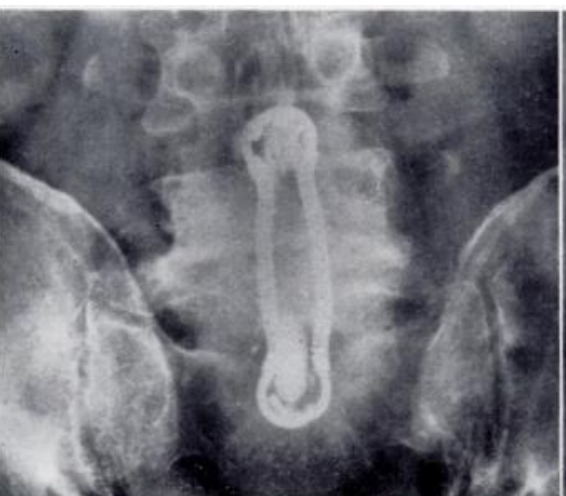

FIG. 6

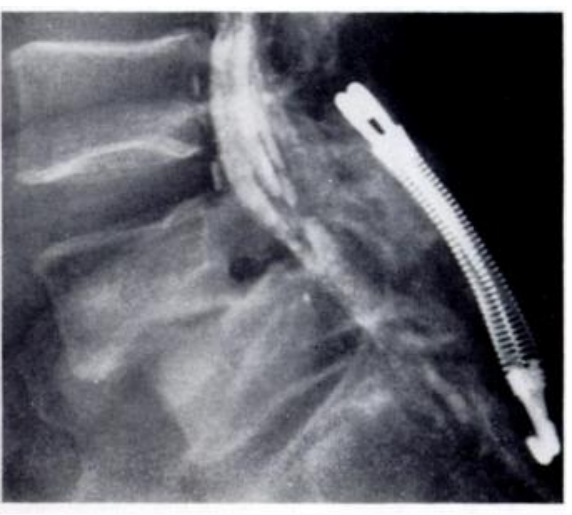

FIG. 7

Figure 5-Radiograph showing spondylolisthesis in a man aged 63. Figures 6 and 7-The same patient three months after lumbo-sacral fusion.

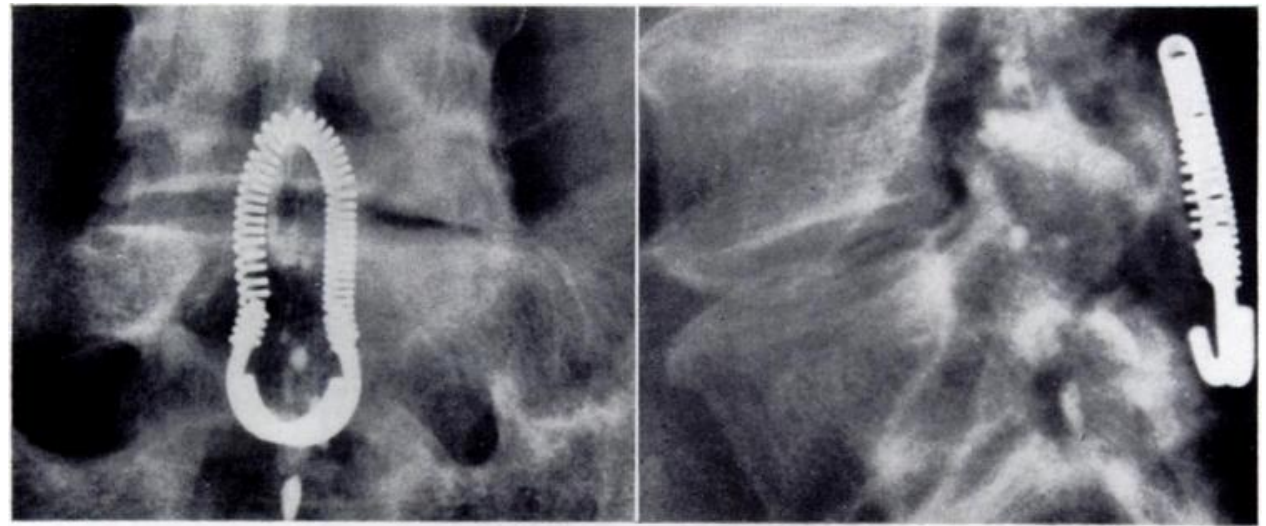

FIG. 8

FIG. 9

Radiographs three years after a one-segment fusion for lumbar disc degeneration in a man of 47 .

THE JOURNAL OF BONE AND JOINT SURGERY 


\section{TECHNIQUE OF OPERATION}

The patient is placed prone on a frame. After the spinous processes and laminae of the lower lumbar spine and sacrum have been exposed through a midline incision the laminae and neural arch of the sacrum are rawed. The opposing edges of the spinous processes are also denuded of cortical bone. Cortico-cancellous grafts are cut from the posterior iliac crest, one longitudinal graft for each side and one transverse graft for each interspinous interval. Anchorage points are now made for the springs. Usually a slot is cut in the superior margin of the uppermost spinous processes and a further slot in the inferior margin of one of the sacral spinous processes. Occasionally at the upper end the springs have been hooked round the superior margin of the lamina. When, as often occurs, the sacral spinous processes are deficient, a hole is carefully gouged or drilled in the neural arch of the sacrum on either side of the midline. The distance between the hook anchorage points is carefully measured and two lengths of spring are cut. The length of each spring needed is calculated from a simple formula which makes allowance for the lengths of the hooks and of the unstretched spring on the screw ends of the hooks. This formula is $\frac{3 X-6}{5}$ where $\mathrm{X}$ is the distance in centimetres between the anchorage points. The result is the length of spring to be cut. Normally a large-radius hook is screwed into each end of both lengths of spring. Both springs are now hooked into the upper anchorage point and after the grafts have been placed in position each spring is carefully stretched until it can be hooked into the lower anchorage point. For the greatest stability the transverse grafts must be wide enough to fit firmly against the rawed edges of the spinous processes and should slightly bow the spring

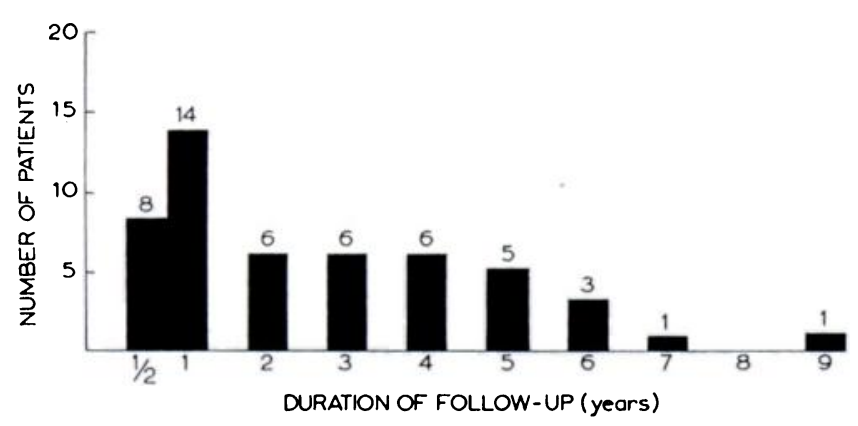

Fig. 10

Histogram showing duration of follow-up of fifty patients after lumbo-sacral fusion.

passing over it, thereby being kept firmly pressed against the longitudinal grafts and vertebrae (Figs. 3 to 7). Sometimes, particularly when only one level is to be fused-for instance the lumbo-sacral joint-it is preferable to use a single length of spring passed round the upper spinous process and hooked into the anchorage hole on either side of the sacrum (Figs. 8 and 9). Cancellous chips are packed into any small gaps between the laminae and the longitudinal grafts. The incisions are closed using suction drainage in the donor site.

Treatment after operation-The patient is nursed flat on a firm bed for two weeks and is then allowed up in a lumbo-sacral corset. The length of stay in hospital is normally under three weeks.

TABLE I

Fifty Patients: Age, Sex and Diagnosis

\begin{tabular}{|c|c|c|}
\hline & & Age (years) \\
\hline \multicolumn{3}{|c|}{ Disc degeneration } \\
\hline Men & 16 & $20-54$ \\
\hline Women & 19 & $22-73$ \\
\hline Total & $\overline{35}$ & \\
\hline \multicolumn{3}{|c|}{ Spondylolisthesis } \\
\hline Men & 7 & $20-62$ \\
\hline Women & 8 & $16-48$ \\
\hline Total & 15 & \\
\hline
\end{tabular}

TABLE II

Grading of Symptoms Before and After Operation

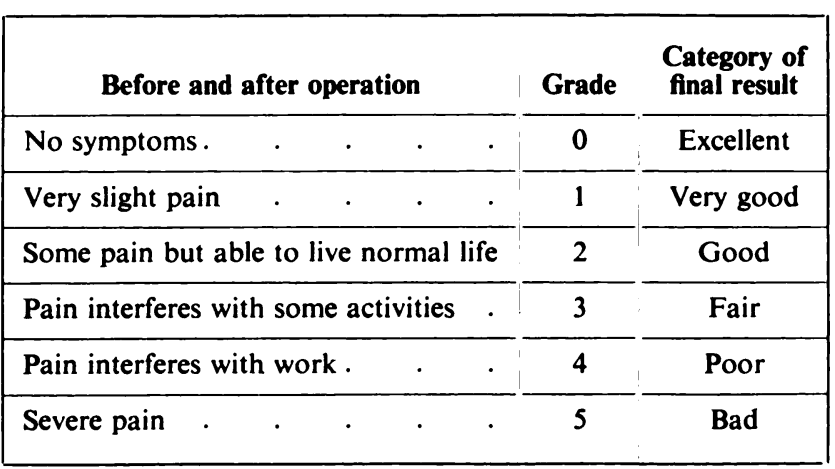

\section{CLINICAL MATERIAL}

From 1963 to 1972 fifty-two patients have had this operation. Two could not be traced. This paper reviews fifty patients, of whom forty-seven attended for examination; two answered a questionnaire and one was assessed from his notes (Table I). The duration of follow-up was from one to nine years after operation (Fig. 10).

\section{RESULTS}

In the assessment of the results the severity of back pain and sciatica before and after operation were graded as shown in Table II.

Clinical assessment of patients with disc degenerationIn twenty-nine of the thirty-five patients, the fusion extended from the fourth lumbar vertebra to the sacrum; in the rest from the fifth lumbar vertebra to the sacrum. Table III shows the results. 
TABLE III

Disc Degeneration. Results in Thirty-five Patients

\begin{tabular}{|c|c|c|c|c|c|c|c|c|c|}
\hline \multicolumn{5}{|c|}{ Severity of symptoms before operation } & \multicolumn{5}{|c|}{ Severity of symptoms after operation } \\
\hline Grade & Backache & $\begin{array}{l}\text { Backache } \\
\text { and } \\
\text { sciatica }\end{array}$ & Sciatica & Total & Backache & $\begin{array}{l}\text { Backache } \\
\text { and } \\
\text { sciatica }\end{array}$ & Sciatica & Total & $\begin{array}{c}\text { Assessment } \\
\text { of } \\
\text { results }\end{array}$ \\
\hline 0 & & & & 0 & & & & 15 & Excellent \\
\hline 1 & & & & 0 & 3 & & 3 & 6 & Very good \\
\hline 2 & & & & 0 & 4 & 3 & & 7 & Good \\
\hline 3 & & & & 0 & 3 & 1 & & 4 & Fair \\
\hline 4 & 3 & 8 & & 11 & 1 & 1 & & 2 & Poor \\
\hline \multirow[t]{2}{*}{5} & 7 & 17 & & 24 & & 1 & & 1 & $\mathrm{Bad}$ \\
\hline & & & & 35 & & & & 35 & \\
\hline
\end{tabular}

TABLE IV

Spondylolisthesis. Results in Fifteen Patients

\begin{tabular}{|c|c|c|c|c|c|c|c|c|c|}
\hline \multirow[b]{2}{*}{ Grade } & \multicolumn{4}{|c|}{ Severity of symptoms before operation } & \multirow[b]{2}{*}{ Backache } & \multicolumn{4}{|c|}{ Severity of symptoms after operation } \\
\hline & Backache & $\begin{array}{l}\text { Backache } \\
\text { and } \\
\text { sciatica }\end{array}$ & Sciatica & Total & & $\begin{array}{c}\text { Backache } \\
\text { and } \\
\text { sciatica }\end{array}$ & Sciatica & Total & $\begin{array}{c}\text { Assessment } \\
\text { of } \\
\text { results }\end{array}$ \\
\hline 0 & & & & 0 & & & & 11 & Excellent \\
\hline 1 & & & & $\mathbf{0}$ & 4 & & & 4 & Very good \\
\hline 2 & & & & 0 & & & & & Good \\
\hline 3 & & & & 0 & & & & & Fair \\
\hline 4 & 6 & 3 & & 9 & & & & & Poor \\
\hline 5 & 2 & 4 & & 6 & & & & & Bad \\
\hline & & & & 15 & & & & 15 & \\
\hline
\end{tabular}

TABLE V

Overall Results in Fifty Patients

\begin{tabular}{|c|c|c|c|c|c|c|c|c|c|}
\hline \multicolumn{5}{|c|}{ Severity of symptoms before operation } & \multicolumn{5}{|c|}{ Severity of symptoms after operation } \\
\hline Grade & Backache & $\begin{array}{l}\text { Backache } \\
\text { and } \\
\text { sciatica }\end{array}$ & Sciatica & Total & Backache & $\begin{array}{l}\text { Backache } \\
\text { and } \\
\text { sciatica }\end{array}$ & Sciatica & Total & $\begin{array}{l}\text { Assessment } \\
\text { of } \\
\text { results }\end{array}$ \\
\hline $\mathbf{0}$ & & & & $\mathbf{0}$ & & & & 26 & Excellent \\
\hline 1 & & & & 0 & 7 & & 3 & 10 & Very good \\
\hline 2 & & & & 0 & 4 & 3 & & 7 & Good \\
\hline 3 & & & & $\mathbf{0}$ & 3 & 1 & & 4 & Fair \\
\hline 4 & 9 & 11 & & 20 & 1 & 1 & & 2 & Poor \\
\hline 5 & 9 & 21 & & 30 & & 1 & & 1 & Bad \\
\hline & & & & 50 & & & & 50 & \\
\hline
\end{tabular}




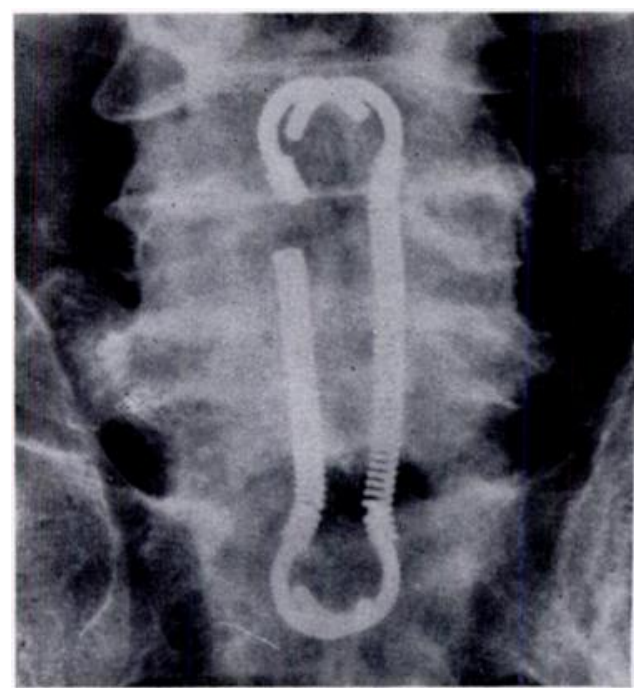

Fig. 11

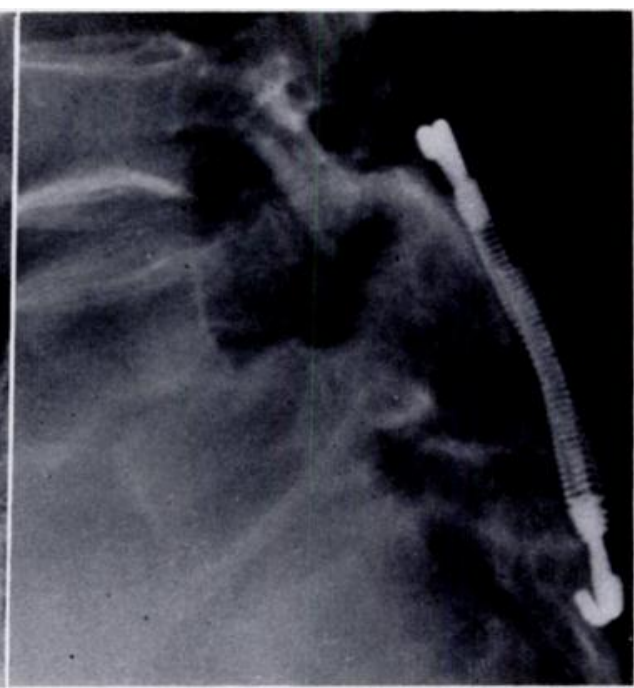

Fig. 12

Same patient as shown in Figures 5 to 7 three years after operation. There is a massive bone graft. One spring has broken but the patient has no symptoms.

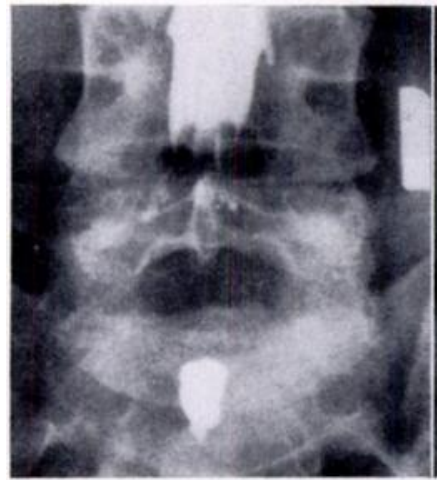

FIG. 13

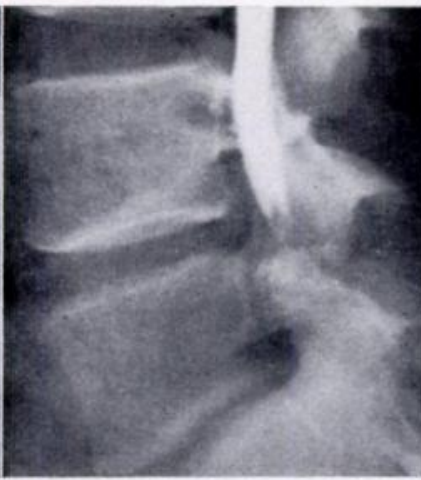

FIG. 14

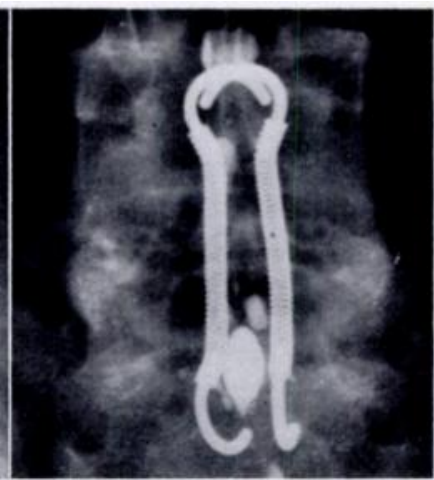

FIG. 15

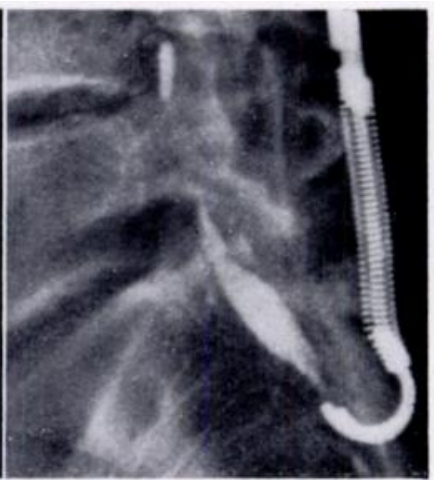

FIG. 16

Figures 13 and 14-Radiographs of male farm worker, aged 34, showing large disc protrusion between the fourth and fifth lumbar vertebrae. Figures 15 and 16-Same patient after removal of disc protrusion and immediate lumbo-sacral fusion. Three months after operation he was doing his full work as a farm labourer.

The only patient who failed to gain any relief had had three previous explorations of the lumbar spine and has since undergone spino-thalamic tractotomy with only very temporary relief. The two patients with poor results had jobs involving heavy lifting: one was a fireman and the other a cellarman. Fifteen patients ( 43 per cent) are free of all symptoms and are graded as excellent. Six are graded as "very good" and seven as "good". A total of twenty-eight ( 80 per cent) are graded as "good" or better, all being able to lead a normal life. No patient was made worse.

Clinical assessment of patients with spondylolisthesis-In thirteen of the fifteen patients, the fusion extended from the fourth lumbar vertebra to the sacrum; in two from the third lumbar vertebra to the sacrum. The degree of forward slip varied from none to almost the full width of the vertebral body. Table IV shows the results. Eleven ( 73 per cent) are free of all symptoms and the remaining four have only slight symptoms and are classified as "very good". All fifteen (100 per cent) are therefore classified as "excellent" or "very good".

All patients-Table V shows the results for disc degeneration and spondylolisthesis combined. Seventy-two per cent of results are "excellent" and "very good" and 86 per cent are "good" or better.

Radiological assessment-It has been found impossible to assess fusion radiologically. Strain films were found to be of little value. The appearance of a pseudarthrosis can be very deceptive because the graft may become a solid mass of bone apparently incorporated with the laminae and spinous processes in the fusion area, yet there may still be a crack in the graft. In one patient, a girl of eighteen with spondylolisthesis, the springs became detached from their lower anchorage because of a fault in technique. This was apparent in the radiographs taken two days after operation. She was kept in a plaster bed 
for three months, and six months after operation the radiograph showed a solid mass of bone with no evidence of pseudarthrosis. However, she again developed severe low back pain and at a further operation two years later a hairline crack was found in the graft. This was cut out and packed with cancellous bone, and new springs were inserted. She rapidly became free of symptoms.

Complications-There were no deaths in this series. Two patients had deep vein thrombosis, followed in one by a pulmonary embolus. Minor superficial wound breakdown occurred in two patients but there were no permanent sequelae. There was no case of deep infection. In eight patients one or both springs were found to be broken in subsequent radiographs but such breakage was never within the first three months after operation (Figs. 11 and 12). This late breakage did not affect the results because all eight patients had "excellent" or "very good" results.

\section{DISCUSSION}

The literature contains many descriptions of the methods and results of posterior lumbo-sacral fusion as well as anterior interbody and intertransverse methods (Adkins 1955; Bosworth, Fielding, Demarest and Bonaquist 1955; Freebody, Bendall and Taylor 1964). Posterior fusion, although the easiest, has always had the most uncertain fusion rate, being as low as 70 per cent (Newman 1965).
Boucher (1959) described a simple method of facet fixation by screws which decreased the failure rate of fusion, but complications from nerve root irritation by screws badly placed or of the wrong length have occurred. The method described here has been safe and reliable and is mechanically sound.

If rigid materials are used in internal fixation of bone, immobilisation will not remain rigid for long. In the case of the lumbo-sacral spine the mechanical strains at the junction of the mobile lumbar spine and the fixed sacrum make it particularly likely that screws will loosen and that wire will either cut through the bone or break. It is believed that the use of resilient springs will largely overcome this failure of fixation. This seems to be borne out by the results in this series. Some springs did break, but none before three months after operation and most over a year later. It is assumed that breakage was from metal fatigue but because the patients with spring breakage had very good or excellent clinical results the springs were not removed.

The rigidity of fixation achieved by the use of springs has enabled most patients to return to their normal activities rapidly even if the work has been heavy. Two farm labourers returned to tractor driving within two months of operation and to full farm work within three months (Figs. 13 to 16). One patient, a motor mechanic, was back to his normal work within four weeks of operation.

The springs and hooks are made by Howmedica.

We wish to thank Mr M. B. Devas for permission to review his patients and for his help in the preparation of this paper.

\section{REFERENCES}

Adkins, E. W. O. (1955) Lumbo-sacral arthrodesis after laminectomy. Journal of Bone and Joint Surgery, 37-B, $208-223$. Attenborough, C. G. (1955) Lumbo-sacral fusion. Journal of Bone and Joint Surgery, 37-B, 165.

Bosworth, D. M., Fielding, J. W., Demarest, L., and Bonaquist, M. (1955) Spondylolisthesis. Journal of Bone and Joint Surgery, 37-A, 767-786.

Boucher, H. H. (1959) A method of spinal fusion. Journal of Bone and Joint Surgery, 41-B, 248-259.

Freebody, D., Bendall, R., and Taylor, R. D. (1971) Anterior transperitoneal lumbar fusion. Journal of Bone and Joint Surgery, 53-B, 617-627.

Newman, P. H. (1951) Lumbo-sacral fusion by Chandler's method. Journal of Bone and Joint Surgery, 33-B, 463.

Newman, P. H. (1965) Lumbo-sacral arthrodesis. Journal of Bone and Joint Surgery, 47-B, 209-210. 